\title{
Case fatality ratios for serious emergency conditions in the Republic of Ireland: a longitudinal investigation of trends over the period 2002-2014 using joinpoint analysis
}

Brenda Lynch ${ }^{1 *}$, Anthony P. Fitzgerald ${ }^{1}$, Paul Corcoran ${ }^{1}$, Orla Healy ${ }^{2}$, Claire Buckley ${ }^{1,2}$, Conor Foley ${ }^{1}$ and John Browne ${ }^{1}$

\begin{abstract}
Background: In the past decade, the Republic of Ireland has undertaken significant reconfiguration programmes to improve emergency services. During this time the public healthcare system experienced a large real decrease in resources. This study assesses national and regional population outcomes over the period 2002-2014, and whether changes coincide with system reconfiguration and the financial restrictions imposed by the 2008 recession.

Methods: Case fatality ratios (CFRs) were constructed for emergency conditions for 2002-2014. Total emergency conditions and individual condition trends were analysed nationally using joinpoint analysis. National results informed the investigation of trends at a regional and county level using an inverse standard error weighted generalised linear model with a log link to construct funnel plots. County-level CFRs were compared for the first and last 3 years of the period to further investigate the changes to county results over the 13 year period, specifically in comparison to the national-level CFR.

Results: Nationally, there was an annual fall in CFRs (2.1\%). The decline was faster from 2002 to 2007 (annual percentage change $=-3.4 ; 95 \% \mathrm{Cl}-4.4,-2.4$ ), compared to 2007-2014 (annual percentage change $=-1.2 ; 95 \% \mathrm{Cl}$ $-1.9,-0.5)$. The South-East had a lower rate of decrease and the West had a higher rate. Cross sectional analysis of two periods (2002-2004 and 2012-2014) showed high consistency in the counties performance relative to the national CFR in both periods.
\end{abstract}

Conclusion: Change in the national trend coincided with the onset of economic stress on the public health system. Attributing the decline in CFR improvement to economic factors is weakened by the uneven nature of the trend change. No distinct pattern of change was identified among regions which underwent substantial reconfiguration of emergency services.

Keywords: Reconfiguration, Emergency care, Health systems, Regional variations

\footnotetext{
*Correspondence: brendalynch@ucc.ie

'University College Cork, School of Public Health, 4th Floor, Western Gateway

Building, Western Road, Cork City, Ireland

Full list of author information is available at the end of the article
}

(c) The Author(s). 2018 Open Access This article is distributed under the terms of the Creative Commons Attribution 4.0 International License (http://creativecommons.org/licenses/by/4.0/), which permits unrestricted use, distribution, and reproduction in any medium, provided you give appropriate credit to the original author(s) and the source, provide a link to the Creative Commons license, and indicate if changes were made. The Creative Commons Public Domain Dedication waiver (http://creativecommons.org/publicdomain/zero/1.0/) applies to the data made available in this article, unless otherwise stated. 


\section{Background}

Conditions requiring emergency medical treatment are significant contributors to global mortality. Ischaemic heart disease, including myocardial infarction, accounted for almost 16\% of total deaths in 2015 (8.9 million deaths) [1]. Ischaemic and haemorrhagic stroke were the second largest cause of total deaths at $11.3 \%$ (6.3 million deaths) [1]. A further $8.5 \%$ of total deaths (4.7 million deaths) were due to external injuries [1].

Outcomes from serious emergency conditions in the Republic of Ireland (Ireland hereafter) are broadly similar to other Organisation for Economic Co-operation and Development (OECD) countries. Analysis of hospital mortality in Ireland found significant reductions in deaths from acute myocardial infarction, heart failure and ischaemic stroke between 2005 and 2015 [2]. The most recent 2011 analysis by the OECD found in-hospital mortality for ischaemic stroke in Ireland (9.9 deaths per 100 admissions) was higher than the OECD average of 8.5 , but was lower than the OECD average (7.9) for myocardial infarction (at 6.8 deaths per 100 admissions) [3]. In Ireland, no previous research of total case fatality for serious emergency conditions has included patients who die outside of hospital. Also, no research has been performed on outcomes for residents of different geographical regions; the focus continues to be on hospital level outcomes [4-6].

Similar to other countries, emergency care services have been centralised to varying degrees across Ireland in the last decade [7-10]. Common features include reducing access to emergency departments in smaller hospitals, centralising specialist emergency care at a 'hub' hospital, and integrating ambulance and general practice referral protocols for given conditions. This reconfiguration has largely occurred in southern and western regions, which are also the most rural. These changes coincided with the establishment of many international best practice recommendations, clinical programmes and guidelines for the treatment of emergency conditions including stroke, acute myocardial infarction (AMI) and trauma [11-14].

Centralising emergency care services has proven controversial. While patients are theoretically transported directly to services appropriate to the severity of their condition, longer journey times exacerbate underlying risks associated with rural areas [15]. International studies highlight the geographical variation in survival from emergency conditions; there is a greater risk of poorer outcomes due to distance from acute services and the existence of an older more socioeconomically disadvantaged population in rural areas [16-18]. The interactions between rurality and deprivation contribute to the complexity of understanding any variation in total mortality [19]. However, the majority of studies consistently emphasis the impact of hospital closures on in-hospital mortality. The continued focus on this outcome may conceal potential increases to out-of-hospital deaths caused by increased travel times.

In Ireland, the changes to services brought about by reconfiguration have not happened in isolation. From 2008, the country experienced an economic recession which resulted in substantial decreases in funding and staff across the public healthcare service. It is estimated that public funding for healthcare was reduced by $22 \%$ over the period 2009-2013 and staffing of public services fell by $10 \%$ from a peak level in 2007 [20].

Within this paper, case fatality for a number of serious emergency conditions in Ireland over the period 20022014 is investigated at a national, regional and county level. The aim is to describe trends in case fatality and establish if, and how, any changes coincide with reconfiguration events and the timing of the economic recession.

\section{Methods}

\section{Study area and context}

The Republic of Ireland is an island of 70.2 thousand $\mathrm{km}^{2}$ on the west of Europe with a population of 4.8 million [21]. It is divided into 26 counties, which for the analysis of emergency care reconfiguration may be grouped into eight regions based on hospital networks identified by the organisation that delivers public healthcare services in Ireland (Fig. 1) [22].

Regional characteristics and reconfiguration of services are presented in online Additional file 1. Two regions (South and Mid-West) have implemented significant reconfiguration of urgent and emergency care over the period 2012-2014. Four regions (West, North-East, South-East and Dublin-South) have introduced some reconfiguration measures since 2006, but these do not cover all services. The two remaining regions (Dublin Midlands and Dublin North-East) have undertaken no major changes since 2006. Emergency departments were eliminated in four largely rural counties: Clare (2009), Tipperary North (2009), Roscommon (2011) and Monaghan (2009). Four other rural counties did not have an emergency department throughout the study period: Leitrim, Wicklow, Carlow and Longford.

\section{Data sources}

We considered 16 serious emergency conditions, derived from consensus work carried out in the UK, for which the risk of death could be reduced by a well performing emergency care system [23]. The conditions were grouped into three categories; stroke, acute myocardial infarction/cardiac arrest, and 'other' (see Table 1 and Additional file 2).

The incidences of deaths from the selected emergency conditions are available from the Irish Central Statistics Office (see Additional file 3). The incidence of hospital admissions for these conditions is available from the 


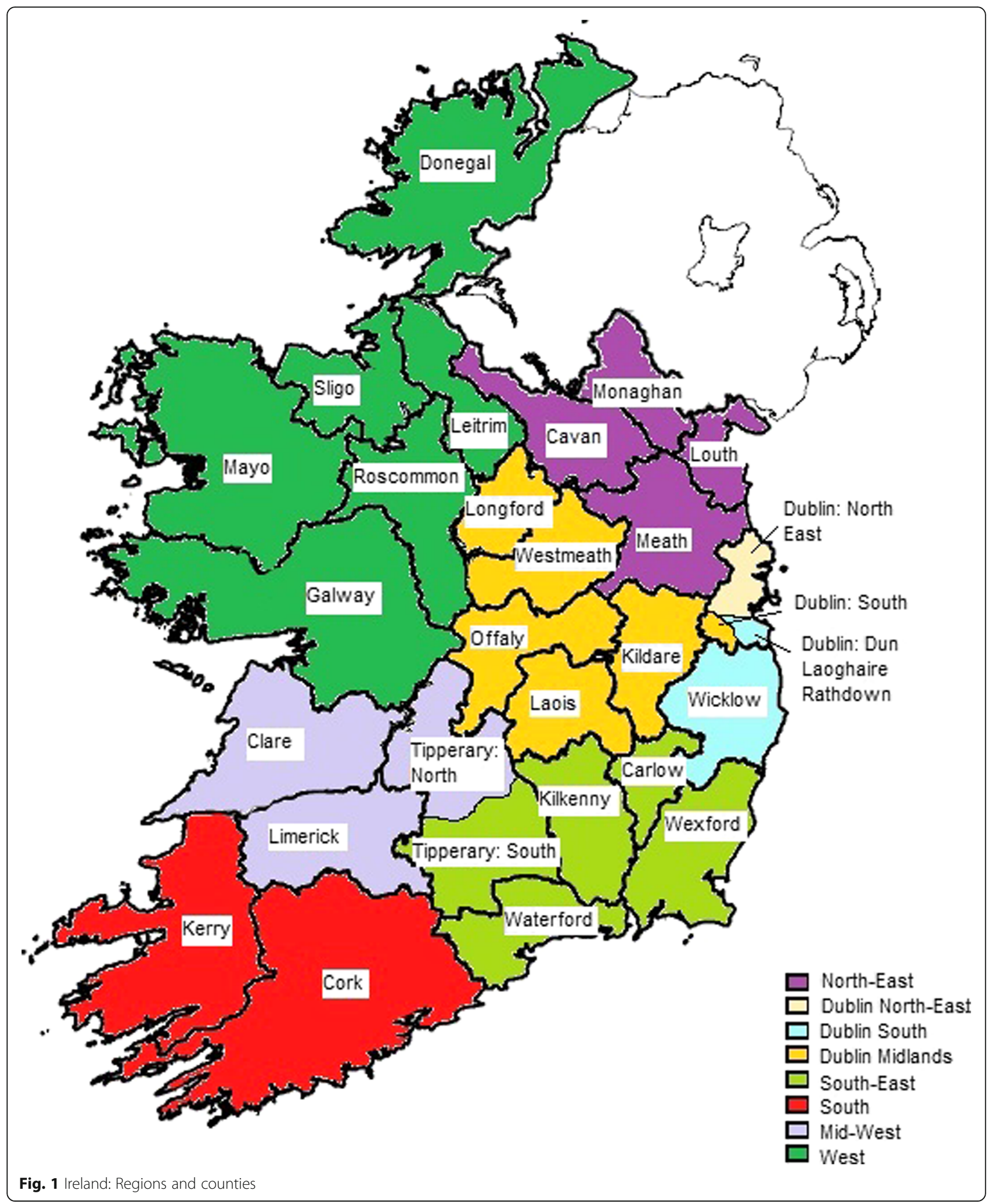

Irish Hospital In-Patient Enquiry (HIPE) admissions system.

The regions and constituent counties analysed are outlined in Fig. 1. Due to concerns regarding the completeness of HIPE data for Roscommon over the period 2011-12, this county has been omitted from all analyses for these years.

Historically, Dublin County has been divided into three sections with respect to emergency care delivery, Dublin 
Table 1 Basket of Emergency Conditions

\begin{tabular}{ll}
\hline 1 & Stroke \\
2 & Acute Myocardial Infarction and Cardiac Arrest (AMI and CA) \\
3 & Other \\
Acute heart failure, anaphylaxis, asphyxiation, asthma, falls under 75, \\
fractured neck of femur, meningitis, pregnancy, road traffic accident, \\
ruptured aortic, self-harm, septic shock, serious head injury
\end{tabular}

North-East, Dublin-South and Dublin Midlands. However, mortality and admissions data is not available at a sub-county level. Therefore, CFRs for Dublin were analysed as a whole and reported independently. As a consequence we only present data for the Midlands part of the Dublin-Midlands region (i.e. counties Kildare, Laois, Offaly, Westmeath and Longford) and for the Wicklow part of the Dublin-South region.

Results produced at a county level also allow for comparisons with routinely collected measures from other administrative data sources.

\section{Statistical analysis \\ National case fatality ratios (CFRs)}

The primary outcome of interest is case fatality ratios (CFR). Annual CFRs from 2002 to 2014 inclusive were calculated. 2002 was chosen as the initial year of analysis as it is the first year that HIPE allows restriction by admission type i.e. emergency admission.

CFRs were calculated by dividing deaths due to the relevant conditions by an estimate of the case incidence. Case incidence was constructed by adding the number of patients who were admitted to a public hospital with one of the emergency conditions and discharged alive after at least a 2 day length of stay, to the number of deaths from that condition (see Additional file 4) [23].

CFRs have been found to be dependent on condition and age, but not sex [23]. Therefore, all CFRs were directly standardised using estimates of the national population's age and case-mix composition in 2014. With 16 conditions and 18 age groups, the age-condition specific CFRs in some regions were small and often zero (see Additional files 3 and 4) [23]. Therefore, conditions were grouped, and ages reduced to those under 65 and then 5 year age groups to $85+$ to allow for meaningful direct standardisation. To adjust for case-mix, the national case incidence rate for each of the condition categories, by age group, were generated and these weights were multiplied by each region and county's case fatality rate.

\section{Joinpoint analysis of national trends}

Joinpoint analysis was conducted on the annual adjusted national CFR observations from 2002 to 2014. This identifies possible change-points where a significant change in the linear trend in national case fatality on a log scale is detected over the study period [24]. The analysis was conducted using the software developed by the Surveillance Research Program Version 4.2.0.1 of USA National Cancer Institute.

Models with a single joinpoint were considered and the optimal piecewise linear model was compared to one with no joinpoints i.e. a straight line. To describe linear trends by period, the estimated annual percent change (APC) is computed for each trend by fitting a regression line to the natural logarithm of the rates using the calendar year as a regressor variable [24]. A negative APC signifies an annual decrease in case fatality, while a positive result denotes an increase. National results were deemed to have a statistically significant change in trend if the results from the estimated regression coefficients for the difference in the slopes had a $P$ value less than 0.05 .

\section{Generalised linear model and funnel plot of regional and county CFR trends}

Longitudinal trends in standardised CFRs were estimated at region and county level using an inverse standard error weighted generalised linear model with a log link, informed by the identified joinpoint in national trends. The inverse standard error allows for precision in comparing areas with differing case populations [25]. Models included the age and case-mix adjusted rate as the dependent variable, with area and an interaction between year and area as independent variables. Trends were compared to the national annual trend using a funnel plot with $95 \%$ limits (+/-2 standard deviations) to identify any areas that differed significantly from the national result.

\section{Cross sectional analysis of county CFRs in two time periods}

A cross sectional analysis was used to compare county CFRs in two different 3 year time periods, 2002-2004, and 2012-2014. The focus on county CFRs allows specific examination of areas that had emergency department closures. Results were compared to the national CFR to establish if a county was above or below the national result in both periods, and a Spearman rank correlation of results was calculated to describe the consistency in a county's performance over the two periods. The coefficient of variation was calculated to determine if the variance between county results had increased or decreased between the two periods. This analysis was conducted using Stata (Version 13).

\section{Results}

National case fatality ratios (CFRs)

Case fatality ratios were constructed for each year from 2002 to 2014 inclusive. For 2002-2004 the national annual CFR was 187 per 1000, falling to 151 per 1000 over the period 2012-2014. The national annual percentage 
change in national total CFRs over the period 20022014 was a decrease of $2.12 \%$.

Between 2002 and 2014 the national total deaths from the selected conditions fell from 7,978 to 5,205, decreasing across all groups (see Additional file 3). Total cases also decreased from 41,645 to 35,736, again decreasing in each group (see Additional file 4).

\section{Joinpoint analysis of national trends}

Joinpoint analysis found a statistically significant change in the CFR trend for total conditions in 2007 (Fig. 2). The APC for the period 2002-2007 was - 3.4 (95\% CI: $-4.4,-2.4)$, with the APC decreasing to $-1.2(95 \% \mathrm{CI}$ : $-1.9,-0.5)$ from 2007 to 2014.

Analysis of the individual condition groups showed a significant change in trend for stroke; from 2002 to 2006 an APC of $-4.3(95 \%$ CI: $-6.2,-2.4)$ was observed, which decreased to -0.6 (95\% CI: -1.4, 0.1) from 2006 to 2014. A significant change was also seen for the 'other' group; from 2002 to 2008 an APC of -2.7 (95\% CI: $-4.6,-0.7)$ was observed, reducing to 0.4 (95\% CI: $-1.7,2.6)$ from 2008 to 2014.
The AMI and cardiac arrest group showed a consistent downward APC of -3.2 over the full period $(95 \%$ CI: -3.5, - 2.9) (Fig. 2).

\section{Generalised linear model and funnel plot of regional and county CFR trends}

Having identified 2007 as the relevant joinpoint in the national trend, analysis of the regional total CFR trend revealed a statistically significant downward trend from 2007 in three regions; Mid-West, West, Dublin (Table 2).

When compared to the national annual decrease ($1.2 \%$ ) for this period, two regions were found to have a statistically significant difference; the South-East had a lower rate of decrease, and the West had a higher rate of decrease (Fig. 3).

The county results identified six counties with significant decreases in their CFR trends (Donegal, Dublin, Kerry, Louth, Mayo, and Sligo) from 2007 to 2014 (Table 2). Carlow and Mayo were found to be outside of the $95 \%$ limit when compared to the national trend (Fig. 3).
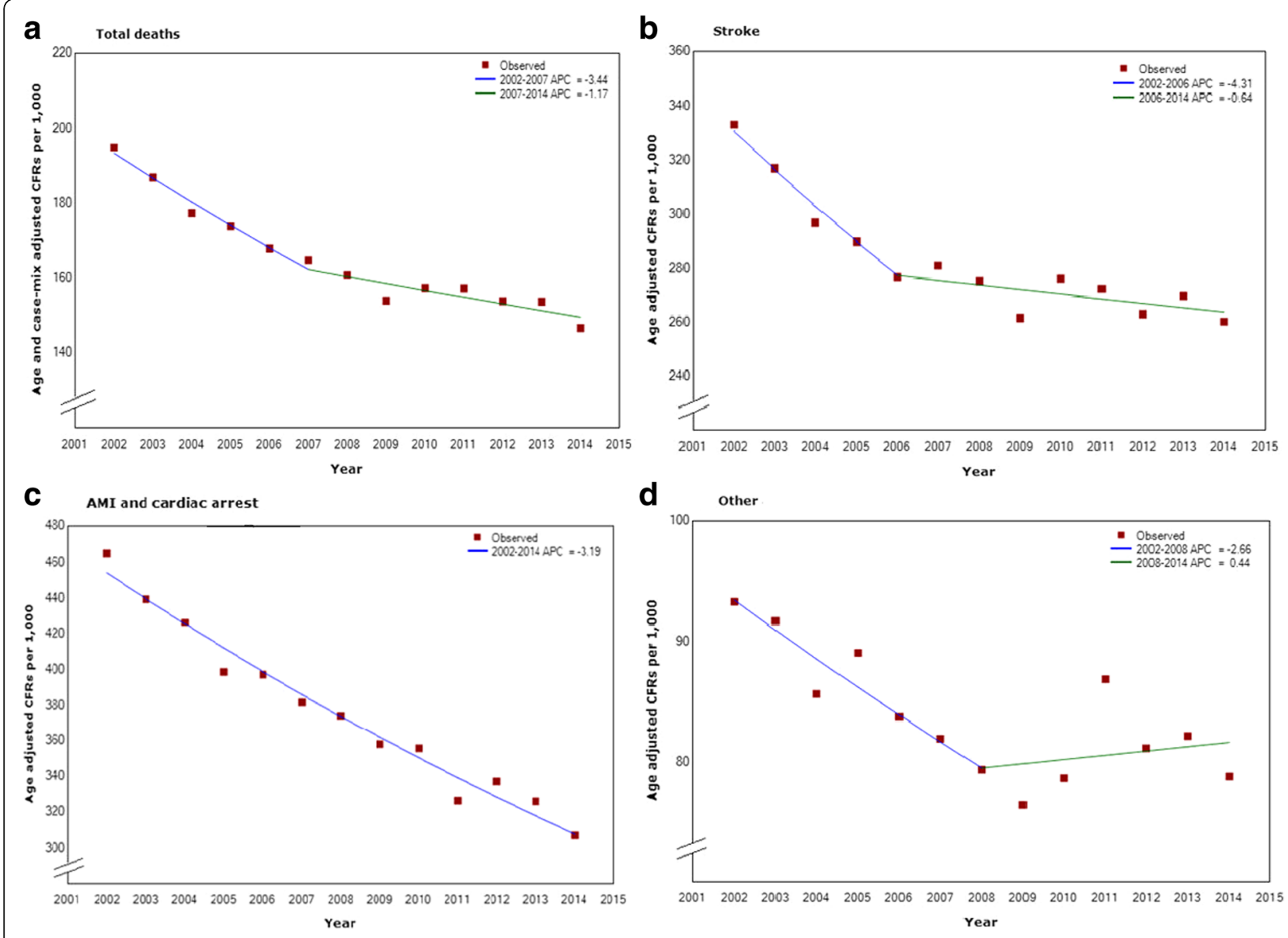

Fig. 2 Joinpoint analyses of adjusted CFRs 
Table 2 Regional and County Annual Percentage Change 2007-2014 and CFRs 2002-2004 and 2012-2014

\begin{tabular}{|c|c|c|c|c|}
\hline & Annual Percentage Change 2007-2014 (95\% Cl) & $P|z|$ & CFR per 1000, 2002-2004 (95\% Cl) & CFR per 1000, 2012-2014 (95\% Cl) \\
\hline Rep. of Ireland & $-1.25(-1.80,-0.70)$ & 0.000 & $187(184,189)$ & $151(149,153)$ \\
\hline \multicolumn{5}{|l|}{ Region } \\
\hline Dublin & $-1.56(-2.62,-0.5)$ & 0.004 & $180(175,184)$ & $138(134,142)$ \\
\hline Midlands & $0.17(-1.34,1.69)$ & 0.823 & $192(185,198)$ & $156(150,162)$ \\
\hline Wicklow & $-0.82(-3.66,2.02)$ & 0.573 & $192(179,204)$ & $154(142,166)$ \\
\hline Mid-West & $-1.83(-3.34,-0.33)$ & 0.017 & $204(197,211)$ & $168(161,174)$ \\
\hline North-East & $-1.4(-2.95,0.15)$ & 0.077 & $166(160,172)$ & $141(135,147)$ \\
\hline South & $-1.05(-2.21,0.1)$ & 0.073 & $197(191,202)$ & $170(165,175)$ \\
\hline South-East & $0.83(-0.58,2.25)$ & 0.249 & $175(170,181)$ & $153(147,158)$ \\
\hline West & $-2.35(-3.44,-1.26)$ & $<0.001$ & $195(190,200)$ & $150(145,155)$ \\
\hline \multicolumn{5}{|l|}{ County } \\
\hline Carlow & $3.18(-0.27,6.63)$ & 0.071 & $187(169,205)$ & $165(148,182)$ \\
\hline Cavan & $-1.91(-4.59,0.78)$ & 0.164 & $169(157,182)$ & $148(134,162)$ \\
\hline Clare & $-2.07(-4.32,0.19)$ & 0.073 & $204(191,218)$ & $163(151,176)$ \\
\hline Cork & $-0.58(-1.66,0.5)$ & 0.293 & $197(190,203)$ & $164(158,170)$ \\
\hline Donegal & $-2.14(-3.95,-0.33)$ & 0.021 & $186(176,195)$ & $140(131,149)$ \\
\hline Dublin & $-1.56(-2.39,-0.73)$ & $<0.001$ & $180(175,184)$ & $138(134,142)$ \\
\hline Galway & $-1.51(-3.14,0.12)$ & 0.070 & $189(181,198)$ & $149(140,157)$ \\
\hline Kerry & $-2.04(-3.69,-0.39)$ & 0.015 & $198(188,208)$ & $189(178,201)$ \\
\hline Kildare & $0.29(-1.79,2.37)$ & 0.785 & $188(176,200)$ & $152(141,163)$ \\
\hline Kilkenny & $-0.3(-3.01,2.41)$ & 0.830 & $166(153,179)$ & $145(132,159)$ \\
\hline Laois & $-0.05(-3.07,2.97)$ & 0.973 & $183(165,201)$ & $146(131,161)$ \\
\hline Leitrim & $0.98(-2.77,4.72)$ & 0.609 & $208(185,230)$ & $171(149,193)$ \\
\hline Limerick & $-0.39(-2.04,1.26)$ & 0.644 & $202(191,212)$ & $179(170,189)$ \\
\hline Longford & $-0.06(-3.59,3.48)$ & 0.975 & $201(181,221)$ & $168(148,187)$ \\
\hline Louth & $-2.48(-4.69,-0.28)$ & 0.027 & $173(162,184)$ & $136(125,148)$ \\
\hline Mayo & $-4.6(-6.31,-2.88)$ & $<0.001$ & $261(249,273)$ & $155(145,165)$ \\
\hline Meath & $-1.38(-3.65,0.88)$ & 0.230 & $154(143,164)$ & $131(121,141)$ \\
\hline Monaghan & $1.47(-1.45,4.4)$ & 0.324 & $173(159,187)$ & $164(147,180)$ \\
\hline Offaly & $-1.56(-4.36,1.24)$ & 0.274 & $200(184,216)$ & $161(145,176)$ \\
\hline Roscommon $^{\mathrm{a}}$ & $-0.38(-2.99,2.23)$ & 0.773 & $147(134,159)$ & $186(165,207)$ \\
\hline Sligo & $-3.31(-6.12,-0.5)$ & 0.021 & $203(187,218)$ & $136(122,150)$ \\
\hline Tipperary & $-1.12(-2.98,0.74)$ & 0.237 & $201(191,210)$ & $154(144,164)$ \\
\hline Waterford & $0.16(-2.17,2.5)$ & 0.892 & $169(158,181)$ & $137(126,149)$ \\
\hline Westmeath & $1.2(-1.32,3.72)$ & 0.352 & $192(177,206)$ & $163(149,176)$ \\
\hline Wexford & $-0.36(-2.31,1.59)$ & 0.715 & $170(159,180)$ & $159(148,169)$ \\
\hline Wicklow & $-0.82(-3.04,1.41)$ & 0.472 & $192(179,204)$ & $154(142,166)$ \\
\hline
\end{tabular}

Roscommon result does not include 2011/2012

\section{Cross sectional analysis of county CFRs in two time periods}

A comparison of county total CFR results in 2002-2004 and 2012-2014 to the respective national CFRs can be seen in Fig. 4, represented by the horizontal and vertical red lines, and Table 1.
The Spearman rank correlation of the CFRs found a statistically significant relationship between county results over the 2 periods $(\rho=0.40, P=0.04)$. Three counties (Monaghan, Roscommon and Wexford) had a decline in their position with regards to the national result between periods, and two counties (Galway and 

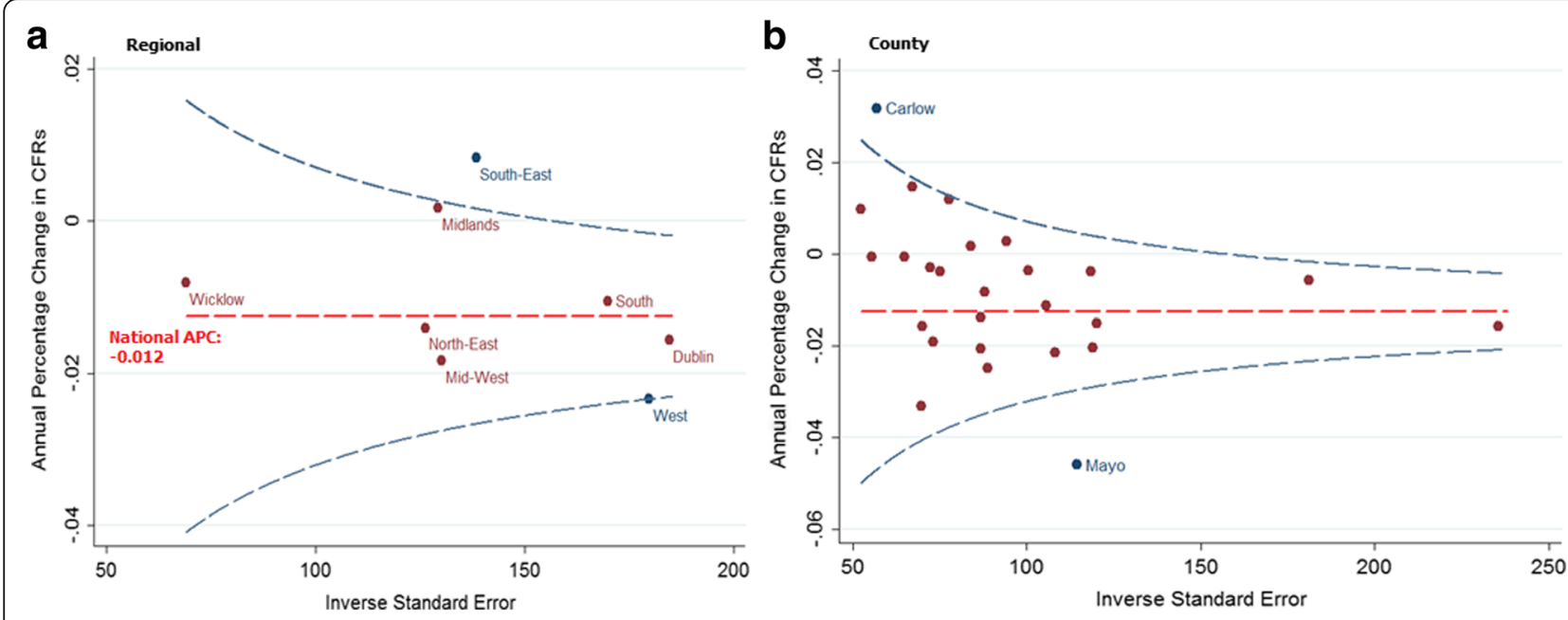

Fig. 3 Annual percentage change (APC) in age and case-mix adjusted CFRs with a 95\% control limit. The target is the national APC of - 1.2\%

Sligo) improved (Fig. 4). The two counties identified as significantly different from the national trend, Carlow and Mayo, were above the national result in both periods.

The coefficient of variation found that variability between county CFRs decreased in the two periods; 11.45 for 2002-2004 and 9.72 for 2012-2014.

\section{Discussion}

\section{Summary of findings}

There was a large decline nationally in case fatality from serious emergency conditions over the period 2002-2014. The continued decrease in case fatality, albeit at a slower rate from 2007, is a positive outcome at a national level. Pronounced changes for stroke and the 'other' group were seen, while the rate of decline for AMI and cardiac arrest did not slow. The number of events for acute myocardial infarction has consistently decreased during the period of study (see Additional file 4). This is despite changes in how the condition is defined, and continued improvements in its detection $[13,26]$.

Variability in outcomes persists at a regional level. Two of the eight regions showed a significant difference in total condition fatality when compared to the 20072014 national rate; the South-East improving slower, while the West improved faster. Variation at county level also demonstrates that within region results are not homogenous.

Cross-sectional analysis revealed many counties in the South-East, North-East and Dublin performed

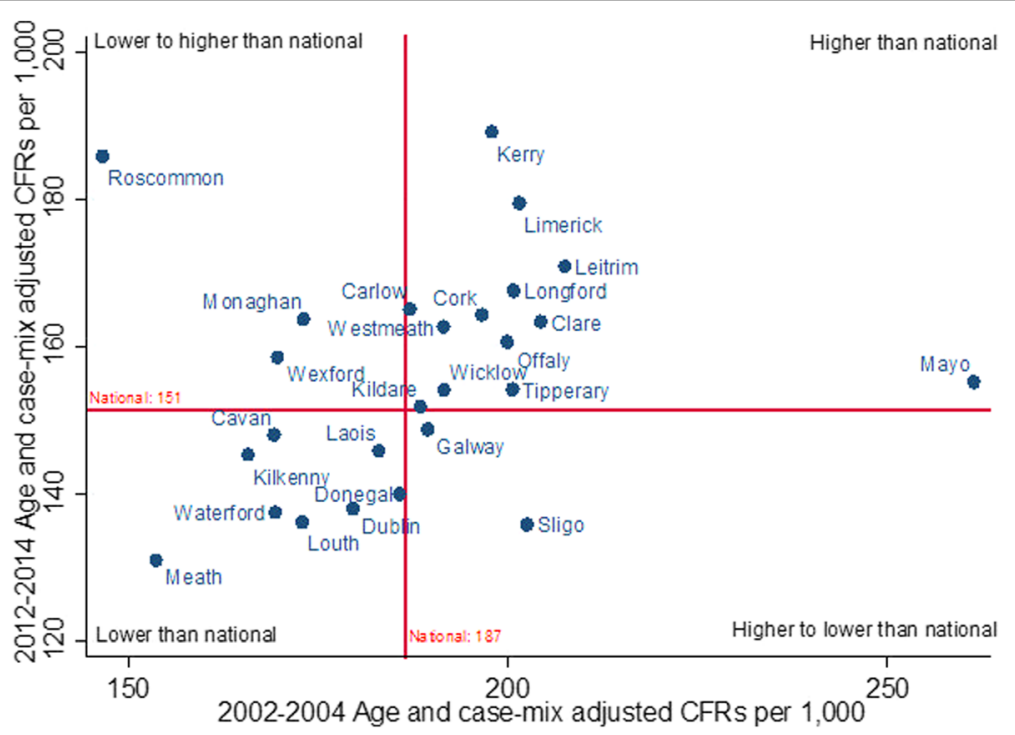

Fig. 4 Comparison of CFRs for 2 time periods; 2002-2004 and 2012-2014 
consistently better than the national CFR. These regions underwent limited attempts at reconfiguration. The South, Mid-West and Midlands regions were consistently worse than the national average CFR over the study period. Of these, the South and Mid-West regions underwent significant reconfiguration.

There is little evidence that identified changes in CFRs at a regional or county level were associated with the reconfiguration of services, such as the removal of emergency departments. For example, counties such as Monaghan and Roscommon, which experienced the closure of emergency departments, saw a decrease in their position relative to the national CFR over the two time periods (2002-2004 and 2012-2014) studied. However, the rate of CFR decrease in these counties was not statistically different from the national rate between 2007 and 2014, as per the constructed funnel plots.

\section{Interpretation}

The findings from this research reveal a complex picture. Undoubtedly outcomes have improved over the period in question; however the national rate of improvement slowed in the most recent years. An argument can be made that mortality may be the last thing affected by system change. Clinical professionalism may limit any potentially negative consequences of such changes. Aspects of quality, safety and morbidity, including a delay in care and unrelieved pain, may be more likely to experience adverse effects.

The concentration of emergency care to specialist centres is intended to improve outcomes [11-14]. In the UK, for example, the reconfiguration of trauma care services led to a $60 \%$ improvement in the odds of surviving a major trauma over the period 2008-2014 [27]. The findings presented in this paper suggest that reconfiguration in Ireland, mainly implemented after 2006, has not resulted in improved outcomes, and has not altered long-term geographical differences between regions and counties. This may be due to poor resourcing and implementation of reconfiguration plans. It may also be due to long-term structural differences between geographical areas in social determinants of health such as rurality and deprivation. Any detailed cross sectional analysis of variations between counties would need to account for these characteristics. A study of mortality in England and Wales found that deprivation accounted for the majority of differences seen between urban and rural areas, with the exception of lung cancer, respiratory disease and accidents [19].

The period of study also saw improved clinical guidelines and documents of best practice, the establishment of offices of clinical audit, as well as the introduction of clinical care programmes for conditions such as stroke and AMI.
The National Stroke Programme launched in 2010 is considered to have substantially changed the level of specialised stroke care received by patients [28]. A 2015 national audit of stroke highlighted in-hospital improvements for stroke mortality, decreasing from 19 to $14 \%$ since 2008 [29].

One of the principal aims of this programme was the development of stroke units in all hospitals which accept stroke patients [28]. However, issues exist regarding the full implementation and staffing of these units. According to the audit, only $29 \%$ of patients were admitted directly to a stroke unit and almost $50 \%$ did not receive treatment in a unit during their stay in hospital [29]. Also, nearly a quarter of the hospitals providing acute stroke care did not meet the minimum standards of a stroke unit [29].

The goal of full national 24/7 thrombolysis has still not been achieved. It is currently supported through bypass protocols to larger tertiary hospitals when required, and the development of the Telemedicine Rapid Access for Stroke and Neurological Assessment (TRASNA). TRASNA allows doctors to provide consultations via video and supervise thrombolysis where necessary. Where implemented the rate of thrombolysed patients is 1 in every 3.5 patients, compared to 1 in 5 elsewhere [28]. However, delays have been experienced in the full roll out of this programme [28].

In terms of cardiac care, the Acute Coronary Syndromes (ACS) Programme was launched in 2012 [30]. This programme has supported the adoption of five 24/7 primary percutaneous coronary intervention $(\mathrm{PCI})$ centres and one 9-5 Monday to Friday centre nationally [31]. Improvements have also been made to pre-hospital services for patients as a result of changes to pre-hospital emergency care council and ambulance protocols. It has subsequently been reported that the number of reperfused ST-Elevation Myocardial Infarction (STEMI) patients that receive PCI increased from 55\% in 2011 to $94 \%$ in 2015 [31].

The impact of these condition specific service changes and other clinical programmes, together with higher level system changes, can be seen in the results of our analysis. The slowing of improvement, particularly for stroke, may now be a result of gains being harder to achieve as programmes start to focus on more complex changes. At a regional level, initial emergency care system resources and quality of care were not uniform and the implementation of reconfiguration differed widely across regions. Changes took place in the context of an initial period of national investment and growth, followed by an economic recession. Budgetary cuts were a contributing factor to the structural changes which resulted in the closure of emergency services. Restrictions on staff recruitment across emergency departments and 
ambulance services continue to be experienced to date. For instance, a review of the National Ambulance Service (NAS) in 2015 found that almost 300 additional staff would be required to cover best achievable performance [32], while the 2016 National Service Plan highlighted the continued gap between pre and post-recession employment in the acute hospital sector [33].

\section{Context of the literature}

The restructuring of emergency services has been previously studied internationally, particularly with regard to the closure of rural emergency departments. Conflicting results have been found. Some studies [15, 34] have found a risk of higher mortality when distance to treatment is increased. In the UK, a study found that a $10-\mathrm{km}$ increase in straight-line distance to treatment was associated with a $1 \%$ absolute increase in mortality [15]. Conversely, a study in the United States concluded that higher in-hospital mortality did not necessarily occur after the closure of a local emergency department [35]. It argued that where other appropriate services exist, the closure or reduction of certain services will not have a negative impact on in-hospital mortality outcomes [35]. However, remaining facilities must be adequately resourced and staffed to meet new demands [36].

\section{Strengths and limitations}

A strength of this study is the shift from in-hospital mortality as the main measure of outcome. Using hospital mortality rates to predict the quality of hospital care can result in good or average hospitals being penalised [37]. Its continued use in outcome reporting [4-6] over-emphasises the concerns of providers, rather than the needs of the population. Case fatality constructed by area of residence allows analysis of outcomes for those who need to engage with the system, rather than focusing on outcomes from a specific service [23].

This study is subject to a number of limitations. Emergency admissions to private hospitals were not included in this analysis; private hospitals are not required to submit data to the hospital inpatient enquiry system (HIPE). Consequentially, case fatality ratio results reported may represent a maximum level; results for counties with a high level of private hospital usage may be lower than stated here. However, we estimate the impact of private hospital admission on our results is low due to a number of factors. First, there were only five small private emergency departments open in Ireland over the study period and many of those were not open for the full study period. Second, these hospitals generally worked on a 8 am-5 pm schedule, Monday to Friday [38, 39] and during our study period would not have operated a weekend service. Third, private emergency departments generally did not accept the most serious emergency conditions, such as major trauma and acute stroke, over the study period [38-40]. Fourth, serious emergency cases requiring ambulances were not taken to private emergency departments over the study period [38, 39].

Our analyses rely on the accuracy of the HIPE system for recording emergency admissions. A study by the Department of Health in 2013 has confirmed the robustness of the data available from HIPE, specifically as a tool for the development of indicators of quality of care in hospitals [41]. As a result, this data has formed the basis of the National Healthcare Quality Reporting System annual reports [4-6] and such use is in line with the analysis produced within this study. However, within our analysis particular caution should be used when interpreting results for County Roscommon. Due to the absence of a HIPE coder for a period spanning part of 2011-2012 in Roscommon County Hospital, the accuracy of coding is limited for much of the county's patient population.

The primary aim of this study is the evaluation of major system change. Reconfiguration of such a scale is likely to lead to improved results for certain conditions, but the deterioration of results for others. Therefore, to assess the overall impact on the system, the focus is necessarily on aggregated higher level data. The analysis of patients, or each condition, at an individual level is of limited benefit.

Cautions should be taken when using county level data in understanding change in complex, multi-factor situations. However, it is important to note that any lower level analysis is restricted in Ireland due to lack of access to more detailed data. Access to admissions data through the hospital admissions system is limited to county level. Similarly, personal individual level mortality data is unavailable from the Central Statistics Office due to concerns of identifiability.

Ireland also differs from many other European countries in that it does not have a unique patient identifier. This restricts the ability to link individuals to admissions and subsequent death for a specific condition. Therefore, analysis was limited to the ratio of deaths to cases in a year, as opposed to the rate of deaths per cases. There are measures underway as of 2014 to introduce a $\mathrm{Na}$ tional Register of Individual Health Identifiers [42].

\section{Policy implications}

There is currently no independent routine health planning on behalf of populations in Ireland. The majority of planning is done by, or on the behalf of, the provider, the health service executive (HSE). Such planning is primarily based on once off national reports, as previously outlined [7-10], which focus on the performance of the 
provider. This study provides a counterpoint to such reports, and aims to refocus attention to how well populations are served.

Our findings show that changes to the national CFR trend coincided with a period of recession in Ireland. With additional budget allocations as of 2015 [33], further monitoring will determine if there are future improvements to CFRs. Additionally, policies of reconfiguration do not appear to have significantly influenced CFRs. Continued observation will determine if on-going implementation of these policies also result in greater improvements. It may also be argued that much of the variance in case-fatality can be explained by non-health system factors such as deprivation and rurality $[19,43,44]$, which have not been included in our model and merit further investigation.

\section{Conclusion}

National outcomes for serious emergency conditions have improved over the period 2002-2014 in Ireland. However, a slowing of the rate of improvement since 2007 coincided with a period of economic contraction. Changes to fatality trends varied by condition; therefore, results cannot be solely attributed to recessionary factors.

The impact of individual clinical programmes, and subsequent system changes to services such as stroke units and PCI centres, must also be considered.

Persistent geographical variation in case fatality remains despite attempts to reconfigure regional services. A distinct pattern cannot be identified between regions and counties that undertook substantial reconfiguration of emergency services and those that did not. Further research on the role of rurality and deprivation in driving outcome and process variation, the role of regional variation in resources, and the extent to which reconfiguration plans were fully implemented, is planned by the SIREN research collaboration.

\section{Additional files}

\section{Additional file 1: Table S1 Reconfiguration of emergency care systems in Ireland. (PDF 294 kb) \\ Additional file 2: Table S2 Basket of Emergency Conditions by ICD9 and ICD10. (PDF $194 \mathrm{~kb}$ )}

Additional file 3: Table S3 Deaths from emergency conditions used in the indicator analysis by year excluding Roscommon. (PDF 216 kb)

Additional file 4: Table S4 Events from emergency conditions used in the indicator analysis by year excluding Roscommon. (PDF 218 kb)

Additional file 5: Table S5 Number of deaths and survivors by emergency conditions 2002-2014. (PDF 201 kb)

\section{Abbreviations}

ACS: Acute coronary syndromes; AMI: Acute myocardial infarction; APC: Annual percentage change; CFR: Case fatality ratio; Cl: Confidence interval; CSO: Central statistics office; HIPE: Hospital inpatient enquiry; HPO: Health pricing office; HRB: Health research board; ICD: International statistical classification of diseases and related health problems;
NAS: National ambulance service; OECD: Organisation for economic cooperation and development; PCl: Percutaneous coronary intervention; SIREN: Study of the impact of reconfiguration on emergency and urgent care networks; STEMI: ST-elevation myocardial infarction; TRASNA: Telemedicine rapid access for stroke and neurological assessment; UK: United Kingdom

\section{Acknowledgements}

The authors wish to acknowledge the support of the wider SIREN Programme Management Committee; the members of the SIREN Programme Steering Group, particularly the group chair Professor John Higgins; and finally, the SIREN Scientific Advisory Group members, Professor Jon Nicholl, Professor Fiona Lecky, Professor Alicia O'Cathain, Professor Ellen Weber, and Professor Michael Schull. We also wish to thank the staff of the Vital Statistics team in the Central Statistics Office (CSO) for facilitating the collection of mortality data. This research would not have been possible without the data collected through the HIPE system, which is managed by the Healthcare Pricing Office (HPO). Access to the system was facilitated by Health Atlas Ireland.

\section{Funding}

Funding was received from the Health Research Board (HRB), "Funding University College Cork Collaborative Applied Research Grant 2012" (CARG/ 2012/28).

The HRB had no involvement in any aspect pertinent to the study or study design. The HRB also had not role in the collection of data, its analysis and interpretation, or the final writing of this manuscript. Payment has not been received from any pharmaceutical company or other agency.

\section{Availability of data and materials}

The datasets studied during the current study are not publicly available due to agreements made with both the CSO and HIPE regarding potential identifiability of small area data analysed. Some data generated and/or analysed during this study is included in this article (Additional files 3, 4, 5). Further aggregated levels of the data may be available from the corresponding author on reasonable request. As corresponding author, BL, has full access to all the data in the study and had final responsibility for the decision to submit this article for publication.

\section{Authors' contributions}

All authors ( $\mathrm{BL}, \mathrm{AF}, \mathrm{PC}, \mathrm{OH}, \mathrm{CB}, \mathrm{CF}$, and JB) made substantial contributions to the conception and design of this article. $\mathrm{BL}$ and $\mathrm{CF}$ contributed to the acquisition of data; $B L, A F$ contributed to the analysis of data. $B L, A F, P C$, and $J B$ contributed to the interpretation of data. $B L, A F$, and JB drafted the article; $\mathrm{PC}, \mathrm{OH}, \mathrm{CB}, \mathrm{CF}$ revised the article critically for important intellectual content. All authors give final approval of the version submitted. All authors agree to be accountable for all aspects of the work in ensuring that questions related to accuracy or integrity of any part of the work are appropriately investigated and resolved.

Ethics approval and consent to participate

The analysis in this paper was conducted on anonymised secondary administrative hospital data from the Hospital In-Patient Enquiry (HIPE) and mortality data from the Central Statistics Office (CSO). The relevant ethical permissions from each of these organisations was gained to access both datasets. However, neither ethical approval nor consent from individual patients was applicable.

\section{Competing interests}

Dr. Healy is member of the Reconfiguration Forum for Cork and Kerry (having been a member of the Project Team 2008-2011) and is currently seconded to the Department of Health as part of National Establishment of Hospital Groups project team.

\section{Publisher's Note}

Springer Nature remains neutral with regard to jurisdictional claims in published maps and institutional affiliations.

\section{Author details}

${ }^{1}$ University College Cork, School of Public Health, 4th Floor, Western Gateway Building, Western Road, Cork City, Ireland. ${ }^{2}$ Health Service Executive, South/ South West Hospital Group, Ernville, Western Road, Cork, Ireland. 
Received: 20 July 2017 Accepted: 30 May 2018

Published online: 19 June 2018

\section{References}

1. Wang H, Naghavi M, Allen C, Barber RM, Bhutta ZA, Carter A, Casey DC, Charlson FJ, Chen AZ, Coates MM. Global, regional, and national life expectancy, all-cause mortality, and cause-specific mortality for 249 causes of death, 1980-2015: a systematic analysis for the global burden of disease study 2015. Lancet. 2016;388(10053):1459-544.

2. Creedon B, Jones S, McKeown D, Sayers G, Cronin M, Martin J, Cosgrave G, Johnson H, Murphy D, Burke D. National audit of hospital mortality report. 2016, Available from https://www.noca.ie/wp-content/uploads/2016/12/ NAHM-REPORT-FINAL.pdf. Accessed 20 Dec 2016.

3. OECD. Health at a glance 2013: OECD indicators 2013, Available from https://www.oecd.org/els/health-systems/Health-at-a-Glance-2013.pdf. Accessed 13 Oct 2016

4. Department of Health. National Healthcare Quality Reporting System Annual Report 2017. 2017, Available from http://health.gov.ie/wp-content/ uploads/2017/07/NHQRS-2017-Annual-Report.pdf. Accessed 20 July 2017.

5. Department of Health. National Healthcare Quality Reporting System Annual Report 2016 2016, Available from http://health.gov.ie/wp-content/ uploads/2016/07/NHQRS_AR16-Final-July-2016.pdf. Accessed 20 July 2017.

6. Department of Health. National Healthcare Quality Reporting System Annual Report 2015. 2015, Available from http://health.gov.ie/wp-content/ uploads/2015/03/NHQRS-Annual-Report-2014.pdf. Accessed 20 July 2017.

7. Acute Medicine Programme Working Group. Report of the national acute medicine programme. 2010, Available from http://www.hse.ie/eng/services/ Publications/Hospitals/AMP.pdf. Accessed 10 Sept 2016.

8. Health Service Executive. The national emergency medicine programme: A strategy to improve safety, quality, access and value in emergency medicine in Ireland. 2012, Available from https://www.hse.ie/eng/ services/publications/clinical-strategy-and-programmes/the-nationalemergency-medicine-programme.pdf. Accessed 11 July 2016.

9. Higgins J. The establishment of hospital groups as a transition to independent hospital trusts; a report to the minister for health, Dr James O'Reilly, TD. 2013, Available from http://health.gov.ie/wp-content/uploads/ 2014/03/IndHospTrusts.pdf. Accessed 12 Sept 2016.

10. Health Service Executive, Department of Health. Securing the future of smaller hospitals: A framework for development. 2013, Available from http:// health.gov.ie/wp-content/uploads/2014/03/SecuringSmallerHospitals.pdf. Accessed 31 Sept 2016.

11. Lindsay MP GG, Bayley M, Hill MD, Davies-Schinkel C, Singh S, and Phillips S. Canadian best practice recommendations for stroke care (update 2010). 2010, Available from http://www.strokebestpractices. ca/wp-content/uploads/2011/04/2010BPR_ENG.pdf. Accessed 03 July 2017

12. Royal College of Physicians. National clinical guideline for stroke. 2016, Available from https://www.strokeaudit.org/SupportFiles/Documents/ Guidelines/2016-National-Clinical-Guideline-for-Stroke-5t-(1).aspx. Accessed 3 July 2017

13. Steg $P G$, James $S K$, Atar D, Badano LP, Lundqvist CB, Borger MA, Di Mario C, Dickstein K, Ducroca G, Fernandez-Aviles F. ESC guidelines for the management of acute myocardial infarction in patients presenting with ST-segment elevation: the task force on the management of STsegment elevation acute myocardial infarction of the European Society of Cardiology (ESC). Eur Heart J. 2012;33(20):2569-619.

14. Nathens AB, Jurkovich GJ, Maier RV, Grossman DC, MacKenzie EJ, Moore M, Rivara FP. Relationship between trauma center volume and outcomes. JAMA. 2001:285(9):1164-71.

15. Nicholl J, West J, Goodacre S, Turner J. The relationship between distance to hospital and patient mortality in emergencies: an observational study. Emerg Med J. 2007;24(9):665-8

16. Wolfe CD, Tilling $K$, Beech $R$, Rudd AG. Variations in case fatality and dependency from stroke in western and Central Europe. Stroke. 1999; 30(2):350-6

17. Malmivara A, Meretoja A, Peltola M, Numerato D, Heijink R, Engelfriet P, Wild S, Belicza É, Bereczki D, Medin E. Comparing ischaemic stroke in six European countries. The EuroHOPE register study. Eur J Neurol. 2015;22(2):284-e226.

18. Dunn N, Arscott A, Thorogood M, Faragher B, De Caestecker L, MacDonald T, McCollum C, Thomas S, Mann R. Regional variation in incidence and case fatality of myocardial infarction among young women in England, Scotland and Wales. J Epidemiol Community Health. 2000:54(4):293-8.

19. Gartner A, Farewell D, Roach P, Dunstan F. Rural/urban mortality differences in England and Wales and the effect of deprivation adjustment. Soc Sci Med. 2011;72(10):1685-94.

20. Thomas S, Burke S, Barry S. The Irish health-care system and austerity: sharing the pain. Lancet. 2014;383(9928):1545-6.

21. Central Statistics Office. Census 2016 Summary Results - Part 1. 2017, Available from http://www.cso.ie/en/media/csoie/newsevents/documents/ pressreleases/2017/prCensussummarypart1.pdf. Accessed 18 October 2017

22. Health Service Executive. An introduction to the HSE. 2005, Available from http://www.hse.ie/eng/services/Publications/corporate/Intro_to_HSE.pdf Accessed 12 September 2016.

23. Nicholl J, Coleman P, Jenkins J, Knowles E, O'Cathain A, Turner J. MCRU Programme 2006-2010: The emergency and urgent care system, final report p. 2011, Available from https://www.sheffield.ac.uk/polopoly_fs/1.52046!/file/ EUC_System_Final_report_2011.pdf. Accessed 06 June 2016

24. Bosetti C, Bertuccio P, Levi F, Lucchini F, Negri E, La Vecchia C. Cancer mortality in the European Union, 1970-2003, with a joinpoint analysis. Ann Oncol. 2008;19(4):631-40

25. Sterne JA, Egger M. Funnel plots for detecting bias in meta-analysis: guidelines on choice of axis. J Clin Epidemiol. 2001;54(10):1046-55.

26. Thygesen K, Alpert JS, White HD, Jaffe AS, Apple FS, Galvani M, Katus HA, Newby LK, Ravkilde J, Chaitman B. Universal definition of myocardial infarction: Kristian Thygesen, Joseph S. Alpert and Harvey D. White on behalf of the joint ESC/ACCF/AHAWHF task force for the redefinition of myocardial infarction. Eur Heart J. 2007;28(20):2525-38.

27. Department of Health. Major trauma audit: NCEC national clincial audit no. 1. 2016, Available from http://health.gov.ie/wp-content/uploads/2016/12/ MTA-NCA01-web.pdf. Accessed 15 December 2016.

28. Lynch P. Ireland's improving stroke care services. Ir Med Times. 2013, Available from https://www.imt.ie/features-opinion/irelands-improvingstroke-care-services-06-06-2013/; Accessed 31 October 2017

29. McElwaine P, McCormack J, Harbison J. National Stroke Audit 2015. 2015, Available from http://www.lenus.ie/hse/bitstream/10147/596575/1/ 25410IHFNationalStrokeAudit2015.pdf. Accessed 12 December 2016.

30. Patient Safety First, Health Service Executive, Royal College of Physicians. Acute Coronary Syndromes Programme; Model of Care. 2012, Available from http:// www.hse.ie/eng/services/publications/Clinical-Strategy-and-Programmes/ Acute-Coronary-Syndrome-Prog-MOC.pdf. Accessed 1 Nov 2017.

31. Health Service Executive. National Clinical Programmes: Acute Coronary Syndrome, Programme Progress. Available from http://www.hse.ie/eng/ about/Who/cspd/ncps/acs/achievements/. Accessed 1 Nov 2017.

32. Lightfoot Solutions UK Ltd. National ambulance service of Ireland emergency service baseline and capacity review. 2015, Available from https://www.hse.ie/eng/services/publications/NAScapacityreview.pdf. Accessed 21 August 2016.

33. Health Service Executive. Natl Service Plan 2016. 2015, Available from http://hse.ie/eng/services/publications/serviceplans/nsp16.pdf. Accessed 16 September 2016.

34. Avdic D. A matter of life and death? Hospital distance and quality of care Essen: CINCH_Health Econ Res Center. Working Paper Series. 2015;1. Available fromhttps:/cinch.uni-due.de/fileadmin/content/research/ workingpaper/1501_CINCH-Series_avdic.pdf. Accessed 6 June 2018.

35. Hsia RY, Kanzaria HK, Srebotnjak T, Maselli J, McCulloch C, Auerbach AD. Is emergency department closure resulting in increased distance to the nearest emergency department associated with increased inpatient mortality? Ann Emerg Med. 2012;60(6):707-15. e704

36. Albert J, Phillips H. Trauma care systems in the United Kingdom. Injury. 2003;34(9):728-34

37. Abel G, Lyratzopoulos G. Ranking hospitals on avoidable death rates derived from retrospective case record review: methodological observations and limitations. BMJ Qual Saf. 2015;24:554-57.

38. Mater Private Hospital. Emergency Department. 2018. Available from http:// www.materprivate.ie/cork/centre-services/all-services/emergencydepartment/index.xml. Accessed 11 Apr 2018.

39. Beacon Hospital. A\&E / Emergency Department Support: which patients we cannot treat. 2018, Available from https://www.beaconhospital.ie/ emergency-department/. Accessed 11 Apr 2018.

40. Irish Association for Emergency Medicine. An Integrated Trauma System for Ireland. 2014, Available from http://www.iaem.ie/wp-content/uploads/2014/ 
12/IAEM_Position_Paper_-_An_Integrated_Trauma_System_for_Ireland_ 171214.pdf. Accessed 11 Apr 2018.

41. Department of Health. Health Care Quality Indicators in the Irish Health System: Examining the Potential of Hospital Discharge Data using the Hospital Inpatient Enquiry System. 2013, Available from https://www.rte.ie/ documents/news/hcqi.pdf. Accessed 11 Apr 2018.

42. Health Information and Quality Authority. Information governance and management standards for the health identifiers operator in Ireland. 2015, Available from https://www.hiqa.ie/sites/default/files/2017-01/IGMStandards-for-HIO.pdf. Accessed 13 Oct 2016.

43. Thorne K, Williams JG, Akbari A, Roberts SE. The impact of social deprivation on mortality following acute myocardial infarction, stroke or subarachnoid haemorrhage: a record linkage study. BMC Cardiovasc Disord. 2015;15(1):71.

44. Haynes R, Gale S. Mortality, long-term illness and deprivation in rural and metropolitan wards of England and Wales. Health Place. 1999;5(4):301-12.

Ready to submit your research? Choose BMC and benefit from:

- fast, convenient online submission

- thorough peer review by experienced researchers in your field

- rapid publication on acceptance

- support for research data, including large and complex data types

- gold Open Access which fosters wider collaboration and increased citations

- maximum visibility for your research: over $100 \mathrm{M}$ website views per year

At BMC, research is always in progress.

Learn more biomedcentral.com/submissions 